\title{
Enantiomeric Cross-Inhibition in the Synthesis of Oligonucleotides on a Nonchiral Template
}

Jürgen G. Schmidt, Peter E. Nielsen, and Leslie E. Orgel

The Salk Institute for Biological Studies, P.0. Box 85800, San Diego, California 92186

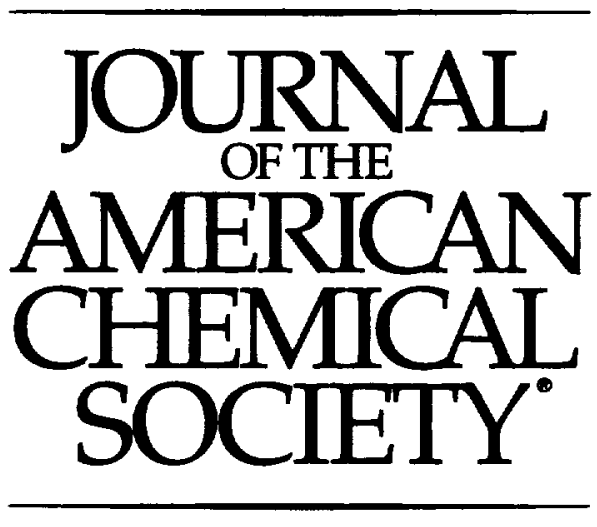

Reprinted from

Volume 119, Number 6, Pages 1494-1495 


\section{Enantiomeric Cross-Inhibition in the Synthesis of Oligonucleotides on a Nonchiral Template}

Jürgen G. Schmidt, Peter E. Nielsen, ${ }^{\dagger}$ and Leslie E. Orgel*

The Salk Institute for Biological Studies P.O. Box 85800, San Diego, Califormia 92186

Received October 14, 1996

Prebiotic syntheses of chiral monomers always yield racemic mixtures. Living systems, however, utilize L-amino acids and D-nucleotides in their biopolymers. The generation of optical asymmetry by selection and amplification in an autocatalytic process is, therefore, an important element in many theories of the origin of life. ${ }^{1-3}$ Replication of polynucleotides in templatedirected syntheses is an obvious candidate for such an amplification step in a pre-"RNA world".4,5 A serious objection to this suggestion is the observation that the efficiency of templatedirected syntheses of RNA is limited by enantiomeric crossinhibition. ${ }^{6}$ Peptide nucleic acids (PNAs), ${ }^{7-9}$ amide-linked, nonchiral analogues of RNA, have been "copied" into RNA 10 and constitute an alternative to chiral polynucleotides as an informational replicating system. Here, we use PNA as model for a hypothetical, nonchiral precursor of RNA in experiments re-examining enantiomeric cross-inhibition. We find that enantiomeric cross-inhibition is as serious in the polymerization of nucleotides on a PNA template as it is on a conventional RNA or DNA template.

L-Guanosine 5'-monophosphate (L-5'-GMP) was synthesized starting from L-ribopyranose (Sigma) following well-established procedures $^{11-15}$ and gave L-5'-GMP in $18 \%$ yield. All analytical data for $\mathrm{L}-5^{\prime}$-GMP were identical to those for the natural D-enantiomer. L-5'-GMP was converted to L-guanosine $5^{\prime}$ phosphoro-2-methylimidazolide (L-2-MeImpG) (Figure 1A) in $95 \%$ yield. ${ }^{16}$ All reaction conditions in our template-directed reactions were chosen to facilitate comparison with previously

\footnotetext{
+Center for Biomolecular Recognition, MMB, Biochemistry B, The Panum Institute, Blegdamsvej 3c, DK-2100 N, Copenhagen, Denmark.

* To whom correspondence should be addressed.

(1) Wald, F. Ann. N. Y. Acad. Sci. 1957, 69, 352-368.

(2) Bonner, W. A.; Blair, N. E.; Dirbas, F. M. Origin Life Evol. Biosphere
}

1981, $11,119-134$.

(3) Ponnamperuma, C.; Chela-Flones, J. Chemical evolution-origin of life: proceedings of the Trieste Conference on Chemical Evolution and the Origin of Life; Ponnamperuma, C., Chela-Flores, J., Eds.; A. Deepak Publishing: Hampton, VA, 1992.

(4) Gesteland, R.; Atkins, J. F. The RNA WORLD. The Nature of Modem RNA Suggests a Prebiotic RNA World; Gesteland, R., Atkins, J. F., Eds.; Cold Spring Harbor Laboratory Press: Cold Spring Harbor, NY, 1993; Vol. Monograph 24.

(5) Joyce, G. F.; Orgel, L. E. The RNA World; Cold Spring Harbor Laboratory Press: Cold Spring Harbor, NY, 1993.

(6) Joyce, G. F.; Visser, G. M.; van Boeckel, C. A. A.; van Boom, J. H.; Orgel, L. E.; van Westrenen, J. Nature 1984, 310, 602-604.

(7) Wittung, P.; Nielsen, P. E.; Buchardt, O.; Egholm, M.; Nordén, B. Nature 1994, 368, 561-563.

(8) Nielsen, P. E.; Egholm, M.; Berg, R. H.; Buchardt, O. Science 1991, $254,1497-1500$

(9) Egholm, M.; Buchardt, O.; Christensen, L.; Behrens, C.; Freier, S M.; Driver, D. A.; Berg, R. H.; Kim, S. K.; Nordén, B.; Nielsen, P. E. Nature 1993, 365, 566-568. 581

10) Böhler, C.; Nielsen, P. E.; Orgel, L. E. Nature 1995, 376, 578-

(11) Recondo, E. F.; Rinderknecht, H. Helv. Chim. Acta 1959, 17, 11711173.

(12) Yoshikawa, M.; Kato, T.; Takenishi, T. Bull. Chem. Soc. Jpn. 1969, 42,3505 .

(13) Hóly, A.; S6rm, F. Collect. Czech Chem. Commun 1971, 36, 32823299.

(14) Vorbrïgen, H.; Krolikiewicz, K.; Bennua, B. Chem Ber. 1981, I14, 1234-1255.

(15) Jenny, T, F.; Benner, S. A. Tetrahedron Lett. 1992, 33, 6619-6620

(16) Inoue, T.; Joyce, G. F.; Grzeskowiak, K.; Orgel, L. E.; Brown, J.

M.; Reese, C. B. J. Mol. Biol. 1984, 178, 669-676.
A)

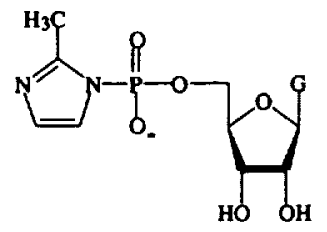

2-MeImpG

B)

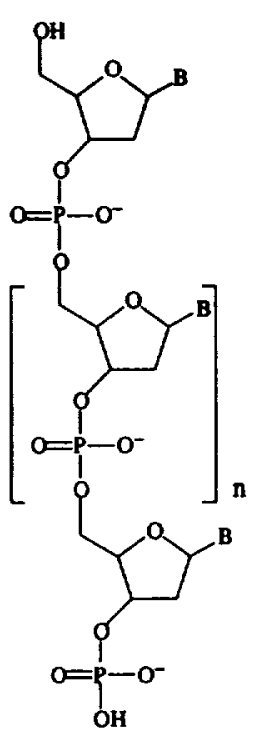

1

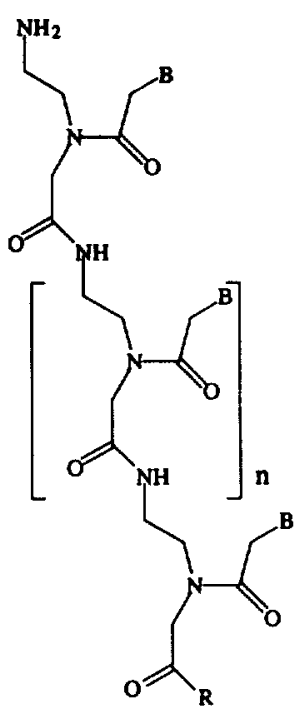

II
Figure 1. (A) Structure of D-2-MeImpG and (B) structure of DNA (I) and PNA (II). The PNA structure has been drawn to emphasize its relation to the standard DNA structure.

published results; all peak assignments are in accord with those established in earlier publications. ${ }^{10,17}$

The reaction of $0.1 \mathrm{M} \mathrm{D}-2-\mathrm{MeImpG}$ gives oligomers up to an octamer in good yields on a DNA $\mathrm{C}_{10}$ template after $24 \mathrm{~h}$ (Figure 2a), whereas the reaction with L-2-MeImpG gives only small amounts of a complex mixture of oligomers up to a maximum length of three (Figure 2b). Two sets of experiments were carried out with racemic mixtures of the activated nucleotides. In the first the concentration was reduced to 0.05 $\mathbf{M}$ for each enantiomer, thereby maintaining the overall concentration of activated nucleotides at $0.1 \mathrm{M}$. In the second set of experiments we used a $0.1 \mathrm{M}$ concentration of each enantiomer to avoid dilution of the D-enantiomer. Oligomerizations using the lower concentration gave oligomers up to only a tetramer with yields diminished from those obtained in the reaction with the $0.1 \mathrm{M}$ D-2-MeImpG alone (Figure $2 \mathrm{~d}$ ). In experiments with $0.1 \mathrm{M}$ each of the nucleotides, higher yields of short oligomers were obtained, but the tetramer was still the longest detectable oligomer (Figure 2c). These results on a DNA template are similar to those reported in an earlier study of enantiomeric cross-inhibition on RNA. ${ }^{6}$

The "nonchiral" PNA $\mathrm{C}_{10}$ strand cannot, in principle, distinguish between the nucleotide enantiomers since it is capable of adopting equivalent left- and right-handed helical conformations. A PNA $\mathrm{C}_{10}$ template, as anticipated, supported almost equally effective oligomerization of D- and L-2-MeImpG (Figure 3, parts a and b). Very minor differences in the efficiency of the reaction and in the product distribution can be attributed to the chiral L-lysine that is attached to the template in order to increase its solubility. ${ }^{8}$ The reaction of a solution

(17) Joyce, G. F. Nonenzymatic template-directed synthesis of informational macromolecules; Cold Spring Harbor Press: Cold Spring Harbor, NY, 1987; Vol. LII, pp 41-51. 
a

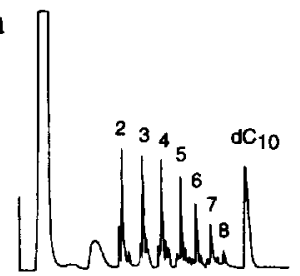

c

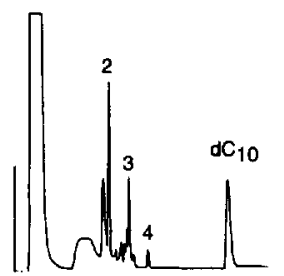

b

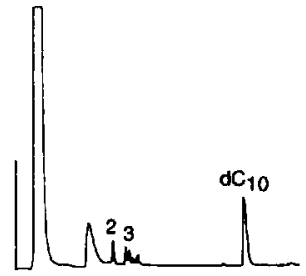

d

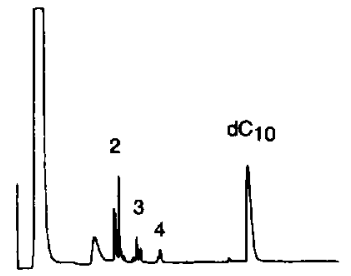

Figure 2. Oligomerization of D-guanosine 5'-phosphoro-2-methylimidazolide (2-MeImpG) on a (dC) 10 template: (a) $0.1 \mathrm{M}$ D-2-MeImpG; (b) $0.1 \mathrm{M} \mathrm{L}$-2-MeImpG; (c) a mixture of $0.1 \mathrm{M}$ D- and $0.1 \mathrm{M} \mathrm{L-2-}$ MeImpG; (d) a mixture of $0.05 \mathrm{M}$ D- and $0.05 \mathrm{M}$ L-2-MelmpG. Reactions were analyzed after $1 \mathrm{~d}$. Reaction conditions: $4^{\circ} \mathrm{C} ; 1.2 \mathrm{M}$ $\mathrm{NaCl} ; 0.2 \mathrm{M} \mathrm{MgCl}_{2} ; 0.005 \mathrm{M}$ template; and $0.2 \mathrm{M}$ 2,6-lutidine buffer, $\mathrm{pH} 7.8$ (at room temperature). Reaction solutions were prepared in 0.7 mL Eppendorf tubes in $5 \mu \mathrm{L}$ volumes. First stock solutions of $\mathrm{NaCl}$ and $\mathrm{MgCl}_{2}$ with the template were coevaporated to dryness. To start the reaction, the residue was redissolved in a freshly prepared solution of 2-MelmpG in 2,6-lutidine buffer. At appropriate times $1 \mu \mathrm{L}$ of a reaction solution was added to $100 \mu \mathrm{L}$ of an aqueous solution containing $0.01 \mathrm{M} \mathrm{HCl}$ and $0.002 \mathrm{M}$ EDTA. The resulting solution ( $\mathrm{pH} \mathrm{2.8-3.0)}$ was kept at $37^{\circ} \mathrm{C}$ for $24 \mathrm{~h}$ to hydrolyze surviving phosphoroimidazoles and then neutralized with aqueous $\mathrm{NaOH}$. A $10 \mu \mathrm{L}$ sample of this solution was mixed with $1 \mathrm{~mL}$ of starting buffer (pH 12) and analyzed by HPLC on RPC-5 as previously described. ${ }^{20,21}$ The reaction products were eluted with a linear gradient of $\mathrm{NaClO}_{4}(\mathrm{pH} 12,0-0.08 \mathrm{M}, 60$ $\mathrm{min}$ ). UV absorption monitored at $254 \mathrm{~nm}$.

containing equal $0.05 \mathrm{M}$ concentrations of $\mathrm{D}$ - and $\mathrm{L}-2$-MeImpG on a PNA $\mathrm{C}_{10}$ template gives only short oligomers, including a trace of the tetramer (Figure 3d). When the concentration of each enantiomer is increased to $0.1 \mathrm{M}$, the yield of short oligomers increases, but the tetramer is still the largest detectable oligomer (Figure $3 \mathrm{c}$ ). This clearly shows that the absence of longer products on a PNA template is due to enantiomeric crossinhibition.

A somewhat more detailed analysis of the HPLC elution profiles is possible. Comparison of Figures $2 \mathrm{a}$ and $3 \mathrm{a}$ shows that the trimer peak is more complex when PNA is used as a template in place of DNA. The individual subpeaks must correspond to $2^{\prime}-5^{\prime}$-linked and pyrophosphate-linked products in addition to the $3^{\prime}-5^{\prime}$-linked products. ${ }^{18,19}$ However, longer oligomers are represented by a single predominant peak in both cases. This suggests that cooperative association with mono-

(18) Bridson, P. K.; Orgel, L. E. J. Mol. Evol. 1980, 144, 567-577.

$\mathbf{a}$

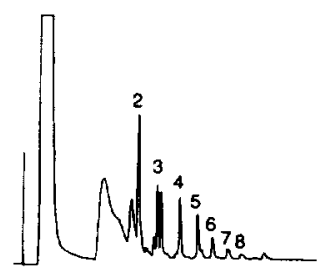

C

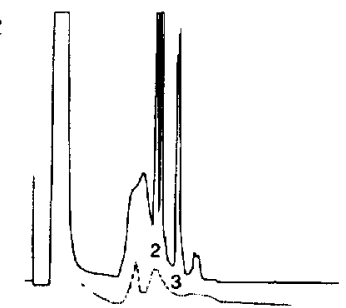

b

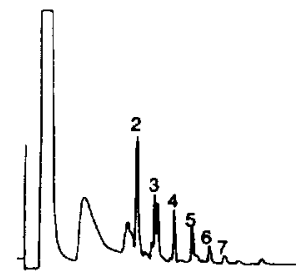

d

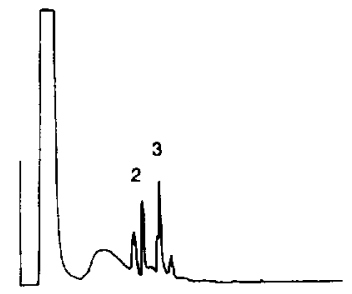

Figure 3. Oligomerization of L- and D-guanosine-5'-phosphoro-2methylimidazolide (2-MeImpG) on a PNA $\mathrm{C}_{10}$ template: (a) $0.1 \mathrm{M} \mathrm{D}-$ 2-MeImpG; (b) 0.1 M L-2-MelmpG; (c) a mixture of $0.1 \mathrm{M} \mathrm{D}$ - and L-2-MeImpG (dashed line gives reaction without template); (d) a mixture of $0.05 \mathrm{M} \mathrm{D}$ - and L-2-MelmpG. Reactions were analyzed after $1 \mathrm{~d}$. Reaction conditions and analysis are as described in the caption to Figure 2.

mers is sufficient to stabilize a helical structure with a DNA template, but a homochiral trimer is required in the case of a PNA template.

We have not studied the PNA-directed reactions of bases other than G. Perhaps enantiomeric cross-inhibition would be less severe for other bases, particularly for the pyrimidines which do not readily adopt the syn-configuration. Nevertheless, it now seems unlikely that the choice of a new template, whether chiral or achiral, will overcome enantiomeric cross-inhibition so generally as to permit the template-directed replication of oligomers long enough to seed the direct emergence of the RNA world from a solution of racemic activated ribomononucleotides. The origin of the RNA world from ribomononucleotides presumably depended on the availability of substrates that were chirally-enriched, selectively adsorbed on chiral mineral surfaces, or synthesized by a chiral catalyst formed in a pre-RNA informational system.

Acknowledgment. This work was supported by grants from NSCORT/EXOBIOLOGY, Grant NAGW-2881 from the National Aeronautics and Space Administration (L.E.O. and J.G.S.), and The Danish National Research Foundation (P.E.N.). We thank Aubrey R. Hill, Jr., for technical assistance and Sylvia Bailey for manuscript preparation.

\section{JA963563C}

(19) Inoue, T : Orgel, L. E J Am Chem Soc 1981, 103, 7666-7667.

(20) Lohrmann, R.; Orgel, L. E. J. Mol. Biol. 1980, 142, 555-567. (21) Joyce, G. F.; Inoue, T.; Orgel, L. E. J. Mol. Biol. 1984, 176, 279- 
